\title{
The Field Limit Between Neurophysiology and Psychopathology Oro-Facial Apraxia
}

\author{
GHEORGHE RAFTU ${ }^{1}$, AUREL NECHITA²*, CRISTIAN CONSTANTIN BUDACU²*, ANCA PORUMB ${ }^{3}$, LUANA ANDREEA MACOVEI \\ ${ }^{1}$ Ovidius University of Constanta, Faculty of Dental Medicine, 7 Ilarie Voronca Str., 900684, Constanta, Romania \\ ${ }^{2}$ Grigore T. Popa University of Medicine and Pharmacy lasi, Faculty of Medecine, 16 Universitatii Str., 700115, Iasi, Romania \\ 3University of Oradea, Faculty of Medicine and Pharmacy, 10,1 Decembrie Sq.,410073, Oradea, Romania
}

\begin{abstract}
Praxia represents the totality of the gestures and movements necessary to perform complex voluntary actions in order to accomplish a goal. Praxia has two aspects: on the one hand, intentional activityand on the other hand a mnestic activity based on memorizing the succession over time and space of the various movements to be performed in order to accomplish the intentional action. Programming the fulfillment of a voluntary action in order to achieve a well-defined purpose proceeds gradually, at different successive levels. The first level is the conceptual one. The person aims to achieve a certain purpose, sets the purpose of the voluntary motor action. The second level is that of the kinetic formulation of action, gesture. The individual disintegrates from the mnesic stock of all kinetic formulas he has learned during his ontogenetic development those formulas that are most appropriate to achieve the proposed action. The third level includes central and peripheral motor innervation, pyramidal, extrapyramidal, cerebellar and medullary motoring ways, which are the peripheral performers of the voluntary action. At this level the harmonious interactions between the different muscles involved in the movements are established, as well as the harmonious innervation of the synergic muscles, fixators, agonists and antagonists. The study comprises 5 patients admitted in the clinic of psychiatry in Constanka, who presented oro-facial-lingual apraxia, apraxic dysphasia and aphasia, appeared in various evolutionary phases of intracranial neoformative processes. Apraxia was due to the increase of the kinetic engraving threshold, to the laughter they are sequenced by the logic of gesture efficiency; the often repeated, deeply fixed, kinetic engraves are automated in time.The co-ordination needed to perform a gestional motor task in order to accomplish a determined action has significant psychological implications.
\end{abstract}

Keywords: intentional activity, mnetic activity, motor innervation, conceptual level.

Praxis results from the combination of three different functional levels: the conceptual level, the level of the kinetic formulation and the peripheral level, of the motor itself. Praxia involves programming and destroying mechanisms.

Gestual amnezia is one of the important components of the practice.

Praxia is one of the forms of motor behaviour, namelya more differentiated aspect of this behaviour. Motor behavior, in turn, is one of the particular aspects of human general behaviour that includes a set of other behaviours (emotional, sexual, social etc.) [1-3].

Our co-ordinated motor activity, carried out in order to achieve a goal, takes place in what we might call the field of action, which can be defined as the totality of the factors that intervene at a given moment, at the particular moment, in the determinism and in the form of praxis motor activity. This field of action is a combination of physiological factors and psychological factors. The realization of the praxis act is the result of an internal cohesion between the subject and the individual. The subject, in the case of the determined praxis action, constitutes a unit with the subject, which, in turn, constitutes at that moment a unity with the whole ambience [4-6].

The action field can be disorganized not in its physiological, butexclusively in the psychological part, and thus leads to gestational incoherence of the demented patient and motorization of the catatonic schizophrenic. The action field is the result of the interaction of complicated physiological and psychological mechanisms and it can be disorganized at different levels, generating different clinical forms of completed motor activity [7-9].

Apraxia is defined as a disorder of gesture activity, in the absence of any paralytic, ataxic or corrective disorder, and keeping the knowledge of the act to be accomplished. Gesture can be preserved, also the conceptual level of the motor act, the knowledge of the act to be accomplished, but the disorder is determined by the lack of normal functional linkage between the kinetic formulation, normally detached, and the realization of this cybernetic form at the peripheral level.

\section{Examination of apraxia}

A number of gestures and actions are being tested. The movements we make during everyday life have varying degrees of complexity and are all executed in order to accomplish a completed action. Examination of an apraxic patient follows, but placing the subject in a particular situation, a test situation that he does not encounter during the day. Thus, one of our sickperson, an aphasic, was properly served by his hands and fingers to execute his spontaneous, ordinary movements, but he could not ask his fingers in the form of $V$ even if he could showed by the examiner how this gesture should be done. Similarly, some apraxists have a spontaneous mimic appropriate to their emotional states, but they can not sketch a smile on the request, mimic the annoyance, weep etc [10-12].

As some apraxis persons are at the same time aphasic, we must first ensure that the sickperson understands what we ask him to do. In cases where there is a great deal of understanding, you are trying to ask the subject to perform an action by showing him the image of this action and objects with a functional correspondent to that action, or is required to imitate the examiner who runs on that meanwhile. In cases of discrete disorder of understanding, we ask the patient to repeat the order, to choose the most appropriate of several other orders, to describe the action

\footnotetext{
*email: aurelnechita@gmail.com; Phone: 0744503660; cristibudacu@yahoo.com; Phone: 0745311060
} 
thathe / she can notfulfill and / or to indicate the subject[ 1315].

It is necessary to note the behaviour of the patient during the execution of the tests. One will put down the interest, the degree of interest in the samples, the time of installing fatigue, the way he realizes the mistakes he makes, the hesitations, the time required for the execution proof, the words he pronounces during the test execution.

To eliminate the existence of an aphasic you will be nonverbal, and one will be asked for the gestural and not the verbal description of the object.

The aptitude for command of the apraxic is tested by examining in turn the non-objectless movements, the object movements and the imitation movements. We note a wrong sequence of gestures in the apraxes required to execute a actions, a perseveration in one of the stages of action, that is the repetition of the same partial gesture that makes up the action. There is often a fusion of the persistent movement with the next movement of the normal sequence. Sometimes the whole course of action is accompanied from time to time by a gesture that persists. Otherwise, the patient appears totally inhibited or totally suppresses some gestures, thus appearing to be totally confused, embarrassed by perplex [16-18].

In some cases, the patient succeeds more or less the first action, but as we ask others, the performance is becoming more and more deficient. Some sick people can not make adequate movements in the absence of the handpiece, but they do it correctly when they have the object in hand.

Other patients manage spontaneously, in appropriate circumstances, to handle the object, but they can not handle it when they are asked to, so one of the sick person properly brushes his teeth in the morning with the toothbrush, but he did not know what to do with it, and finally he used it as a pen, trying to write with it. Another one could not mimic the gesture of drinking from a glass, nor could he mime the drinking from an empty glass, but at home at his table, he serves himself correctly from the glass when drinking water. We must keep in mind that the patient's test must put it in an unusual situation, to ask him somehow to perform [19-21].

Apraxia should not be confused with the lack of a motor initiative in which the patient neglects his or her upper limb, does not use it in their actions, lethim hang inert. But there is no sign of paralysis. If we incite him, he can move the arm correctly and forcefully, but he does not use it spontaneously. In some patients, this symptom translates into the fact that the patient does not carry out any action started or omitted from the chain necessary to accomplish the act.The action isn't wrong, but short, shortened.

\section{The oro-facial apraxia}

The oro-facial apraxia is a form of inertial apraxia characterized by the fact that the patient can not perform voluntary movements of the face and mouth muscles at the examiner's request, independent of the mobility that accompanies expressive speech. The patient can not open and close his mouth on demand, can not show the teeth, make the gesture of the kiss or kiss properly, whistle, crack, reproduce the mimic of laughter, of wonder, of sadness. swallow on order, can not remove the tongue, straightens the tongue to the nose, to the chin, to one cheek, to the corners of the mouth, to the upper lip, can not remove the sound of the tsk-tsk, can not whisper on request. The patient can not shut off one eye individually, can not swell or suck his cheeks, isolated or together, can not blow, can't sip the liquid from the glass through a straw, can not chew on request, can not grab his teeth, with his lips a thing on the table, can not remove a crumb off lips with his tongue, can not imitate chuck, sneeze, can not breathe deep on command, can notbite, can not crook his nose. Sometimes the patient can kiss hand, cheek, but he can not make the gesture of the kiss without object, kiss in the air. It can also blow off a candle, a litmatch, butcan not blow in the air. It can not swallow to order, but it does it correctly in a reflex. In some cases, oro-lingual apraxic disorders are ameliorating when the sickperson makes movements in front of the mirror and can control them. It would be a form of spatial dyskinesia in this case, an oro-facial-linguistic self-topognosy [22-24].

Movement anomalies are varied, sometimes observing dyskonic, spastic and synchinetic contractions. The superior longevity of the face is rarely achieved and rarely the patient can close the eyes to order. Unable to carry it out on order, it is executed correctly when inserted into an automatic activity.

However there are cases in which reflex automatic activity, such as mastication and especially swallowing, are disturbed, unequivocally executed, spastic and insufficiently differentiated.

We had a case, a sick man who could not swallow except when he pushed his food with his finger to the bottom of his mouth.

The patients with oro-facial apraxia have difficulty in executing the movements of the face, mouth, tongue on demand. These difficulties are different of those observed in the facial paresis of central origin in that in the latter the movements are pairs or absent, whereas in the oro-facial apraxia they are mistakenly executed, paraphraxic. Thus, they are asked to crook the nose, lips, then pulling them to the side, making a noise of a squeaking of his mouth. Such paraphractures occur not only at the examiner's command but also when the patient wants to imitate a motion shown by the examiner $[25,26]$.

Generally, as in other forms of apraxia, such disturbances of the face movements are exceptionally met in the same patient as part of his normal behaviour outside the test situation. The wrong action may consist of movements of the required movement. Another variation may be extra movement or noises, such as closing the eyes when whistling, pulling the tongue out with the fingers, etc. Sometimes the patient has persistent repetition of the same movement, correctly executed at the beginning, on any other movement required. Otherwise, the patient fails to perform the required movement at the first attempt but makes successive attempts until he succeeds. Some sick people make only amorphous, insignificant movements, and eventually fail to perform the required movement. If the patient is required to make a gesture to quit a match, and the match is not ignited, he performs it harder than if the match is ignited. The test situation exerts a facilitating action. In most of the cases, the errors consist either of a total lack or of substitutions of movements, perseverences or deformations of movements. Disturbances also concern other coordinated movements than facial movements, such as coughing and rhythmic breathing, respectively. There is no obvious correlation between spontaneous facial expression and degree of apraxia, nor with the presence or absence of a facial paresis.

While facial paresis patients are more or less accentuated by dysarthria, those with facial apraxia do nothave this symptom. Previous injuries, such as in Broca's aphasia, and posterior injuries, such as in aphasia, may produce oro-facial apraxia with or without joint defect. 
Apraxia is rarely located only on the eyelids: the patient can not voluntarily close the eyes either one or both at the same time. Sometimes the patients have an exaggerated synch in the lateral or vertical look. When the command is to look up, the patient contracts the frontal muscles but has an exaggerated retraction of the upper eyelid that precedes or accompanies the movement of the eyeball. This is normal, as well as spontaneous movements are normal.

By some authors, oro-facial apraxia would be a transitory symptom in aphasia, since oral practice movements would be less complex than those of verbal motricity, and some Broca aphasia do not have oro-facial apraxia although this would be expected. On the other hand, it would not be a difference in this regard between expressive and receptive aphasia, oro-facial apraxia being found with the same frequency in both forms[27-29].

It has been shown that the oro-facial apraxia is not only found in Broca aphasia but also in the aphasia of leadership rich speech, deformed by many phomematic paraphases, great disturbances in the repetition of the speech, but with the relatively good preservation of the understanding. There is a statistically significant relationship between the appearance of phonematic paraphases and the oro-facial apraxia, due to the fact that all volitional movements of the face that they are verbal or nonverbal are organized in the same associative field. A lesion of this region leads to a disorder of the muscularity of the face that would translate during the speech through phenomatic paraphases. So understanding the language articulated as well as the recognition of the significance of the movements are decoding performances in the service of communication and regulated by a common neuropsychological mechanism.

The oro-facial-lingual aptitude often accompanies the initial phase of an expressive aphasia. During the regression of these speech disorders, apraxic disorders facial oro-facial correction is relatively rapid, and the expressive speech disorders continue to be maintained. There is a dissociation in the motor activities of the same muscle groups according to their purpose. These same muscle groups function normally during articulatory and phonatory activity and have disorders in the course of their voluntary or even automatic-reflex innervation.

There have also been cases in which oro-facial apraxia occurred in the absence of expressive aphasia. These observations clearly show that expressive aphasia is not a consequence of an apprax of the fonatory apparatus, on the one hand, and on the other hand, that the lesion site in oro-facial apraxia is located in the region of the frontal lobe, perhaps even in the vicinity of the area whose lesion is responsible for Broca's aphasia. It is notew orthy that the surgical sections of the anterior part of the corpus callosus do not give oro-facial apraxia. An ideo-kinetic oro-occipital apraxis was also described which would have other characters than the oro-facial apraxia generally considered melocinetic. Some unilateral brain lesions can cause bilateral disorders of oro-facial activities with functional dissociations, such as an expressive affection with voluntary innervation disturbance (inability to blow, whistle, to draw liquids with a straw, to crack, to voluntary kiss, etc.

Oro-facial-lingual apraxia is commonly associated with anarchy and, more rarely, with expressive aphasia. After some authors, the essential role in producing oro-faciallingual apraxia would be to the frontal lobes in the vicinity of the Broca area. At these levels the production of apraxia is related to both cortical and subcortical lesions[30-32].
Facial apraxia is due to arch fascicular lesions, which link the posterior areas of the tongue with the associative cortex previously located in the facial area.

The most common lesions, such as those produced in or around the Broca area would cut off the connections to the left side of the face. The facial apraxia management has a different clinical picture than the Broca aphasia, especially since the first dysarthria is missing.

The amnesic aphasic makes several mistakes in the verbal command to perform a movement in oro-facial territory, compared to other clinical types of aphasics. In amnesic aphasia there would be a predominance of inadequate verbal responses compared to the same type of answers to the imitation of the oro-facial movement, a phenomenon that can not be explained by the disorder of understanding.

The problems faced by the patient during the examination of the oro-facial apraxis are similar to those who are put on examination of the denomination in the aphasia test. There would be a form of expressive aphasia in which elements of oro-linguo-facial apraxia would intervene. In the idiocytic motor apathy the symptoms of diversion, phonematic derailment predominate during the verbal repetition and naming. The patients have hesitations in pronouncement, interrupt after the first syllable and tend to make persevering efforts to correct themselves. Many times, they simulate verbal amnesia ("do not find the word"), butit's only a pseudo-amnesia, because the patient has the word in mind, knows him, but can not pronounce him because of apraxic phenomena.

Leonhard (1962) has described an ideocinetic motor aphasia, delineating it from the inertial form and which is associated with ideocinetic facial apraxia. Ideocinetic aphasia was due to a loss of kinesthetic image of verbal articular movements. Deficientarticulation, hesitations and phonematic deviations would be explained by the lack of proper phonematic movement. The idiocinetic forms of limb apraxia, oro-facial apraxia and aphasia are caused by essentially similar, but not identical, disorders, which can be observed in isolation.

The lesions that determine these forms would be located in the parietal area. By analogy, it is possible to admit the existence of ideocinetic aggression in which the patient has no paragraphs assimilable with some paraphases. On the contrary, the ideocinetic disorder concerns the very act of graph, being a particular type of isolated apraxy, limited only to the act of writing.

Broca aphasy cases often have elements of ideocinetic apraxia and motoric innervational disorders, the latter being translated by the impossibility of articulated speech, with all the obvious efforts made by the patient in this respect, by the presence of verbal remnants that the patient repeated by imprecision in the expression of phenomena

It would be a disastrous form of aphasia that would be distinct from the ideocinetic form, first through the implications of the latter.

\section{Experimental part \\ Material and method}

The study includes 5 patients admitted to the Clinic of Psychiatry in Constanta, who had oral or facial lingual apraxia, apraxic dysphasia and aphasia, occurring in various evolutionary phases of intracranial neoformative processes.

\section{Results and discussions}

The studied cases show that the damage to the inferior parts of the precentral circumference of the dominant 
hemisphere is necessary, but not sufficient, to determine buco-facio-lingual apraxis. It has been hypothesized that for such apraxia it would be necessary that the functional decompensation act to occur abruptly on a cerebral cortex with a previous poor functional stat". Absence of apraxia in brain tumors located in the lower region of the precentral area would be explained by the fact that, unlike patients with CV lesions in these patients the rest of the brain is in a good functional state, capable of clearing.

One of the classical tests of apraxia, which is to ask the patient to simulate a transitive act without the presence of the object, shows the duality between operation and image. This test requires the imitative representation of the act, but if the latter can play a role in perfection the execution of the act, however, the performance can only be made from a certain level and only when it is quite complex to anticipate them to be successful.

A particular role in the genesis of apraxia is played by the time factor, in the sense of the succession of the various actions. The action plan has a spatio-temporal character. Action takes place in space at a certain time, and the succession of behaviours must follow a certain succesion. In this sense, the kinetic melody has been spoken about, meaning that not only the sequence must be harmonious and appropriate, but also the duration of each component of the action must be appropriate to the purpose; so some movements will be more rapid, others more slowly, composing a melody of the determined elementar acts that make up the complex of the entire action ( Goethe's das Binden und Losen).

\section{Conclusions}

Apraxia is a superior form of motor disorganization/ disray in which a significant role is played by the dislocation of symbolic functions in the field of motoring.

A correct action requires a perception, representation and correct recognition.

Depending on the situation, the way of considering phenomena, the patient's particular state of the moment, his behaviour has a particular aspect.

We can consider disturbances from several points of view: ontogenetic (automatic-non-automatic), representation-voluntaryaction, gnosis-action, perceptionmovement.

\section{References}

1.EDWIN MAAS, KIMBERLY A. FARINELLA Random Versus Blocked Practice in Treatment for Childhood Apraxia of Speech Journal of Speech Language and Hearing Research 2012.

2.DENICE MICHELLE EDEAL, CHRISTINA ELKE GILDERSLEEVENEUMANN, The Importance of Production Frequency in Therapy for Childhood Apraxia of Speech, American J ournal of Speech-Language Pathology 2011.

3.H. TERBAND, B. MAASSEN, P. VAN LIESHOUT, L. NIJ LAND, Stability and composition of functional synergies for speech movements in children with developmental speech disorders Journal of Communication Disorders 2011.

4.J OAN N. KADERAVEK, LAURA M. JUSTICE, Fidelity: An Essential Component of Evidence-Based Practice in Speech-Language Pathology American J ournal of Speech-Language Pathology, 2010.

5.KIRRIEJ. BALLARD, DONALD A. ROBIN, PATRICIA MCCABE, JEANNIE MCDONALD, A Treatment for Dysprosody in Childhood Apraxia of Speech, Journal of Speech Language and Hearing Research 2010. 6.J ONATHAN L. PRESTON, TARA MCALLISTER, EMILY PHILLIPS, SUZANNE BOYCE, MARK TIEDE, JACKIE S. KIM, DOUGLASH. WHALEN, Treatment for Residual Rhotic Errors With High- and Low-Frequency Ultrasound Visual Feedback: A Single-Case Experimental Design, Journal of Speech Language and Hearing Research, 2018.
7.MARIA I. GRIGOS, JULIE CASE, Changes in movement transitions across a practice period in childhood apraxia of speech, Clinical Linguistics \& Phonetics 2018.

8.ANGELA T MORGAN, ELIZABETH MURRAY, FREDERIQUE J LIÉGEOIS, Interventions for childhood apraxia of speech, Cochrane review, 2018. 9.S. ROHRBACH, F. BUETTNER, D. POLLEX, P. MATHMANN, L. WEINHOLD, R. SCHUBERT, R. REILMANN, Quantitative examination of isometric tongue protrusion forces in children with oro facial dysfunctions or myofunctional disorders, Journal of Oral Rehabilitation, 2018.

10.BUHACEANU, R., LUNGU, N.C., FORNA, N.C., et all, Anew Class of Mesoionic4-(1,3-Dithiol-2-ylium)phenolates, Rev.Chim.(Bucharest), 64, no.8,2013, p.803-807

11.BUHACEANU, R., LUNGU, N.C., FORNA, N.C et all,The Influence of Bromine Substituent on Optical Properties of Some 1,3-Dithiolium Derivatives, Rev.Chim.(Bucharest), 64, no.9,2013, p.960-964

12.COSTAN, A.; DIMA, A.; IONITA, l.; et al., Thermal properties of a TI$6 \mathrm{AL}-4 \mathrm{~V}$ alloy used as dental implant material ,Optoelectronics and Advanced Materials- Rapid Communications, Volume: 5 Issue: 1-2 Pages: 92-95,2011

13.CHECHERITA,. L.E., FORNA ,N.C., STAMATIN, O.,et al., Correlations between biochemical parameters integrated in stomatognathic system dysfunctional syndrome, Rev.Chim. (Bucharest), 64, no.10,2013, p. 1172-1181

14.FORNA N, CIMPOESU N; SCUTARIU MM; ET al, Study of the electrocorrosion resistance of titanium alloys used in implantology, Book Group Author(s): IEEE, Conference: 3rd International Conference on E-Health and Bioengineering (EHB) Location: Univ Med \& Pharm, Iasi, ROMANIA Date: NOV 24-26, 2011

15.ANTOHE, M.E., AGOP FORNA, D.,DASCALU,C.G.,FORNA, N.C., The importance of observing the aesthetic requirements in partial edentulous rehabilitation - implications in medical-dental training, International Journal of education and information technologies Volume: 10 p. 199-203,2016

16.CHECHERITA, L.E., FORNA, N.C., SURDU MACOVEI, A., et al. Influence of chemical therapeutical methods on manducatory muscles, Rev.Chim.(Bucharest), 64, no.11, 2013, p. 1312-1316

17.MINCIUNA, M.G., VIZUREANU, P., ACHITEI, D.C., Structural characterization of some CoCrMo Alloys with medical applications, Rev.Chim.(Bucharest), 65, no.3, 2014, p.335-338

18.MANCIUC C., DOROBAT C., DANAILA C., et al., Lymphoma in an HIV-positive patient,Medical surgical journal,119(1), 2015,pg.97-100

19.ANTOHE, M.E., AGOP FORNA, D., DASCALU, C.G., Implications of digital image processing in the paraclinical assessment of the partially edentated patient, Rev.Chim.(Bucharest), 69, no.2, 2018, p.521-52

20.COSTEA C.F., TURLIUC M.D., DIMITRIU G.,ET AL., Inflammatory juvenile compound conjunctivalnevi.A.clinicopathological study and literature review,Romanian J ournal of morphology and embryology, 58(3),2017, pg.739-747

21.COPCIA, V.E., HRISTODOR, C.M., DUNCA ,S., IORDANOVA, R., BACHVAROVA-NEDELCHEVA, FORNA, N.C., SANDU, I., Synthesis and Antibacterial Properties of ZnO/Clinoptilolite and TiO2/ZnTiO3/ Clinoptilolite Pow ders. Rev. Chim. (Bucharest), 64, no.9, 2013, p.978981.

22.POPESCU, E, AGOP FORNA, D, EARAR, K., FORNA, N.C, Bone substitutes used in guided bone regeneration technique review, Mat.Plast., 54, no.2, 2017, p. 390-392

23.GURAU, G., DINU, C.A., EARAR, K., ,et al, Diagnostic Value of chemical and hematological markers in children acute abdominal pain, Rev.Chim.(Bucharest), 67, no.3,2016 ,p:507-511

24.STOIAN,A., EARAR, K.,BUDACU,C.ET AL., No association between antioxidant enzyme gene polymorphism and Albuminuria in Type 2 Diabetes Mellitus Cases, Rev.Chim. (Bucharest), 67, no.11, 2016, p. 2355

25.ANTOHE M.,ANDRONACHE M, FEIER R, STAMATIN O, FORNA NC, Statistical studies regarding therapeutic approaches for edentulous social clinical cases in student,,spractical stages, Romanian Journal of Oral rehabilitation, 9(2),2017,94-99 
26.AGOP FORNA, D, FORNA, N.C, EARAR ,K., POPESCU, E. ,Postoperative clinical evolution of edentulous patients treated by guided bone regeneration using xenograft bone substitute and collagen membrane, Mat.Plast., 54, no 2, 2017, p. 312-315

27.EARAR, K., CERGHIZAN,D., SANDU, A.V., MATEI ,M.N., LEATA ,R. SANDU, I.G., BEJINARIU , C., COMAN,M.,. The Role of Functional Polymers in the Optimization of the Acrylic Biomaterials Used in Removable Prosthetic Restoration - II. Assessment of traction test and antifungal activity. Mat.Plast., 52, no.4, 2015, p.487-493

28.CALIN,A.M., DEBITA,M,DRAGOMIR, R., et al.Treatement methods conditioned by the gravity of drug-induced gingival hyperplasias, Rev.Chim.(Bucharest), 68, no.11,2017, p.2618-2622

29.BENEA, H.R., EARAR, K., LATTANZI, W., et al., Collagen scaffold and lipoaspirate fluid - Derived stem cells for the treatment of cartilage defects in a Rabbit Model, Rev.Chim.(Bucharest), 69, no.2, 2018, p.515-520.

30.MAFTEI,D.,ASAFTEI,I.V.,SANDU.I., et al.,Conversion of industrial feedstock mainly with butanes and butenes over HZSM-5 and Zn/ HZSM-5(nitrate)catalysts, Rev.Chim.(Bucharest), 66, no.5,2015, p.673680

31.GRIGORE,A.M.,BUSILA, C., CHESARU, I.B., et al., Biological featurea of tumors results of experimental studies, Rev.Chim.(Bucharest), 68, no.3,2017,p, 594-598

32.EARAR, K., ANTONIAC, V.I., BACIU, S., et al., Etching treatment effect on surface morphology of dental structures, Rev.Chim.(Bucharest), 68, no.11, 2017, p. 2700-2703.

Manuscript received 11.03 .2018 